\title{
UM PONTO NO INFINITO DO ESPAÇO: A GEOGRAFIA LIBERTÁRIA DE ÉLISÉE RECLUS SURGIU ANTES DA HORA? ${ }^{1}$
}

\author{
A POINT IN THE INFINITY OF SPACE: DID ÉLISÉE RECLUS'S \\ LIBERTARIAN GEOGRAPHY EMERGE AHEAD OF ITS TIME?
}

\author{
UN POINT DANS L'INFINI DE L'ESPACE: LA GÉOGRAPHIE \\ LIBERTAIRE DE ÉLISÉE RECLUS A SURGI AVANT LHEURE? \\ José Vandério Cirqueira - Instituto Federal de Goiás - Formosa - Goiás - Brasil \\ vanderioifg@gmail.com
}

\begin{abstract}
Resumo
0 objetivo principal deste trabalho é demonstrar o contexto de formação do pensamento geográfico de Élisée Reclus e o papel da sua obra na história da geografia. A experiência espacial e a prática revolucionária foram elementos que contribuíram com o modo de pensar desse geógrafo francês. Por outro lado, a pesquisa científica e o envolvimento com o pensamento acadêmico de sua época marcou a organização de sua obra. 0 caráter social libertário da geografia de Reclus influenciou decisivamente a forma como a historiografia dominante recebeu o seu conteúdo mais engajado.
\end{abstract}

Palavras-chave: Élisée Reclus, geografia libertária, pensamento geográfico, historiografia dominante.

\section{Abstract}

The main objective of this paper is to address the context surrounding the emergence of Élisée Reclus's geographical thought and the role of his work in the history of geography. Spatial experience and revolutionary practice were elements that contributed to the French geographer's way of thinking. On the other hand, scientific research and involvement with the academic concepts of his time affected the organization of his work. The libertarian social nature of Reclus's geography ultimately influenced the way the dominant historiography viewed its more politicized content.

Keywords: Élisée Reclus, libertarian geography, geographical thought, dominant historiography.

\section{Résumé}

Le présent travail a pour principal objectif de démontrer le contexte de la formation de la pensée géographique de Élisée Reclus et le rôle de son oeuvre dans l'histoire de la géographie. L'expérience spatiale et la pratique révolutionnaire ont été éléments qui ont contribué à la pensée du géographe français. De l'autre côtê, la recherche scientifique et l'engagement avec la pensée académique de son temps a marqué l'organisation de sonoeuvre. Le caractère social libertaire de la géographie de Reclus a influencé de manière décisive la façon dont l'historiographie dominante a reçu son contenu le plus engagé.

Mots clés: Élisée Reclus, géographie libertaire, pensée géographique, historiographie dominante.

\section{Introdução}

Buscar entender como a forma em que o pensamento geográfico de Élisée Reclus (1830 - 1905) foi construído pôde contribuir com a reflexão acerca do que foi mais definitivo no processo de afirmação e de 
negligência dessa geografia. Por sua vez, a medida como foi constituído esse pensamento leva à compreensão dos caracteres marcantes dessa geograficidade e a relação que ela teve com o pensamento de sua época, como a contribuição direta ou indireta à geografia que estava sendo feita e os efeitos complicadores decorrentes do seu esquecimento.

\section{Pensamento geográfico germinado na experiência espacial}

Da mesma forma que a geografia de Reclus está imersa em uma determinada época e, por isso, está marcada pelos efeitos constitutivos da geografia em voga, fazendo parte dessa regularidade discursiva permeada pelo prisma do pensamento ocidental, também ele, enquanto indivíduo nascido no interior da França, numa família humilde, se relacionará com esse mundo europeu que está imbuído de experiências particulares. Entretanto, as escolhas pessoais que o geógrafo fez, como os caminhos que ele pôs a seguir e as posições que tomou, incidiram decisivamente sobre a conformação de sua geografia, em parte marcada por descontinuidades discursivas.

A abordagem acerca das regularidades e das descontinuidades discursivas é feita por Foucault (2013). As descontinuidades são o que ele classifica como territórios arqueológicos, pois não pertencem a um domínio modelar de cientificidade com proposições que obedecem às mesmas leis de construção. Por serem oriundas de diversas matrizes epistemológicas, ou de uma única matriz, mas que não se restringe ao temário ou ao arquivo enunciativo de uma única regularidade discursiva, elas promovem a descontinuidade discursiva, não ensejando o status científico hierarquicamente organizado.

No caso da geografia de Reclus, essa descontinuidade discursiva é baseada em dois pilares centrais: o discurso das liberdades, que almeja a organização espacial; e o discurso do equilíbrio, relacionado à autogestão do território. Essas modalidades discursivas soaram como essencialmente incompatíveis ao projeto de geografia da época, bem como ao modelo de sociedade, de mercado e de Estado nacional que o próprio pensamento geográfico era tributário.

Acerca do caráter da experiência espacial, constitutivo da formação da geografia reclusiana, é recorrente a interpretação do pensamento despersonalizado e desvinculado do seu criador, em virtude de buscar demonstrar que as informações apresentadas são tão neutras que não se contaminam com a vivência daquele que a escreveu. 
A tentativa dessa forma de narrativa que estabelece a cisão entre autor, obra e contexto é de demonstrar que a originalidade das palavras e a potência do discurso estão divorciadas do seu emissor, estão desterradas dos lugares em que foram construídas e emitidas, e são atemporais à época em que estão submetidas.

O pensamento geográfico de Reclus entendido como um ponto no infinito do espaço enseja questões: $\mathrm{O}$ que se encontra no percurso político reclusiano que é fruto das experiências geográficas? Por outro lado, o que se encontra na sua escrita geográfica que é fruto das experiências políticas?

Em Reclus, não há evidente cisão entre sua geografia e sua vida, entre a forma como ele experimentou geograficidades diversificadas e como ele contou essas narrativas, nem entre a forma como ele se posicionou diante das questões de ordem social e política com o grau de seu engajamento, com as problemáticas evidentes de sua época. Ele encarou a vida e a política de forma semelhante ao que Onfray (2001, p. 14) classifica de biografia existencial, na qual "o hedonismo está para a moral assim como o anarquismo está para a política: uma opção vital, exigida por um corpo que se recorda [...]", pois ele "não imagina uma filosofia sem o romance autobiográfico que a torna possível".

Desse modo, Onfray (2010) demonstra que a história da filosofia buscou separar a vida da obra do autor, e esse exemplo também serve para alguns casos da história da geografia, havendo a necessidade de colocá-los de volta ao mundo material, pois essa cisão levava à mitificação do sujeito e à leitura genérica ou superficial de sua obra.

Donde a necessidade de uma íntima relação entre teoria e prática, reflexão e vida, pensamento e ação. A biografia de um filósofo não se resume ao simples comentário das suas obras publicadas, mas à natureza da ligação entre seus escritos e seus comportamentos. Somente o conjunto se chama uma obra. Mais que qualquer outro, o filósofo tem o dever de manter ligados esses dois tempos, com tanta frequência opostos. A vida alimenta a obra, que, por sua vez, alimenta a vida. [...]

A teoria propõe uma prática, visa uma prática. Fora disso, ela não tem nenhuma razão de ser. Numa lógica nominalista, as palavras servem de maneira utilitária e não são nada mais que instrumentos práticos. Não há religião do verbo. (Onfray, 2010, p. 25)

E o que mais buscou Reclus em toda sua vida foi produzir uma obra alimentada de seu projeto existencial, alimentada de suas experiências 
geográficas e históricas ${ }^{3}$, e que essa obra poderia ser revertida numa prática espacial, não a convertendo em uma religião do verbo, dando seu sentido nominalista, essencialmente utilitário, transformando devaneios em prática, retroalimentando sua vida rebelde e inquieta.

O seu interesse não era transformar sua geografia na voz altiva do centro, a serviço da verbalização transcendental, ou da coerciva evolução do saber geográfico dirigido pelas academias dominantes. Por isso é pluridiscursiva sua geografia, pois estava sendo feita de vida, de suor, alegria e prazer, de sangue, de luta e de liberdade, para ser útil para a mesma vida de suor, sangue, luta, alegria, prazer e liberdade em que ela foi gestada. Não era para ser uma geografia de gabinete, que somente compusesse o edifício acadêmico ortodoxo e as práticas opressoras do capital e do Estado. Era para ser desde o início uma geografia dissidente, guardada a devida forma de radicalidade para a época, presente na geograficidade das lutas sociais de transformação do espaço.

A crítica historiográfica mais heterodoxa tece progressivos debates dos anos de 1970 até hoje, cada um a seu modo, acerca do impacto negativo do esquecimento da geografia libertária reclusiana para a história do pensamento geográfico, sobretudo Giblin (1976), Boino (1999, 2010), Lacoste (2005), Mosquete (2007), Alavoine-Muller (2009), Sanguin (2009), Roques (2011), Creagh (2011a), Pelletier (2011), Ferretti (2012), entre outros. Essa questão resvala não somente diante da impermeabilidade montada pela academia, mas da impossibilidade de ter levado essa obra, e conjuntamente seu caráter libertário, como um todo, à práxis científica e social.

De um modo geral, ocorre a permanência de duas formas de produção do conhecimento: "uma prática teórica de gabinete, e um engajamento existencial na vida cotidiana” (Onfray, 2010, p. 22). Isso é muito comum na geografia vivida por Reclus. Mas ele optou por fazer uma geografia que, embora científica, sustentada em modelos de explicação da realidade, na coleta de informações, no tratamento, discussão e apresentação de sínteses, na descrição, comparação, experimentação, quantificação e análise, entre outros procedimentos, por sua vez, era essencialmente apregoada pela perspectiva do engajamento existencial, tendo os espaços e suas manifestações dialéticas de classes, e seu mergulho nesse oceano complexo do social, o substrato para a formação de seu ser e de sua geograficidade. 
Essas duas formas de pesquisadores (a do geógrafo de gabinete e a do engajamento existencial) têm maior impacto nas ciências humanas e sociais, com detalhe ao caso da geografia, pois o objeto de estudo é a própria realidade espacial que eles estão envolvidos. A perspectiva do engajamento existencial configura-se também no espectro pessoal do pesquisador viajante, cosmopolita nômade, que transpõem as seguras fronteiras nacionais, envolvendo-se com diversas culturas e conhecendo distantes lugares. Entretanto, a do geógrafo de gabinete se caracteriza como o pesquisador sedentário, presente no fortalecimento do saber, na configuração de refinadas sínteses, na promoção e divulgação dos resultados, amante da identidade nacional ou regional, dos costumes locais, por estar envolvido pela perspectiva patriótica nacionalista

No caso de Reclus, ele se configura pelo espectro do viajante nômade, mas também em parte, no do pesquisador sedentário, comprometido com o desenvolvimento de seus projetos teóricos, suas metas, o necessário esforço de síntese e de apresentação dos resultados. Até sua morte fez as duas coisas; nos últimos dez anos de sua vida tornou-se professor universitário, deixou sua obra concluída, mas não se eximiu de suas viagens, inclusive não morreu em casa, mas em Thourout, próximo a Bruxelas (Reclus, 1911).

"Mais tarde, bem mais tarde, cada um se descobre nômade ou sedentário, amador de fluxos, de transportes, de deslocamentos, ou apaixonado pelo estatismo, o imobilismo e as raízes"4 (Onfray, 2007, p. 10, tradução minha). Reclus foi mais amador de fluxos do que apaixonado pelas raízes. Mas um não anula o outro, é originalmente os dois, e sua geografia é formada pelas duas bases, a do viajante e a do agente envolvido pelas questões cotidianas locais, caso de sua forte atuação na Confederação Juraciana e na Comuna de Paris, culminando em suas análises das comunas.

O mais importante é demonstrar que a geografia de Reclus foi sendo construída ao passo de suas experiências existenciais, do embate radical e a luta de classes, em que se posicionou em defesa das trabalhadoras e dos trabalhadores, vinculado ao socialismo libertário. Por muitas vezes, são desenvolvidos trabalhos que evidenciam com maior intensidade a vida política de Reclus, seu envolvimento com a militância e a participação nas lutas históricas emblemáticas do século XIX, em que ele vivenciou, exemplo da participação nos círculos revolucionários da I Internacional, o confronto ideológico e de estratégia de ação entre marxismo e anarquismo, a luta armada etc. Essas pesquisas fazem incisiva 
separação entre o contexto ideológico e o contexto da produção geográfica, descaracterizando a importância de se observar que o pensamento ideológico e seu engajamento político, e o pensamento geográfico e seu engajamento científico, em Reclus, são uma mesma coisa, pois ambos foram formados diante das mesmas inquietações.

Evidentemente que, no discurso geográfico reclusiano, não se encontram tão explícitas noções ideológicas como é facilmente encontrado nos textos políticos, caso de A evolução, a revolução e o ideal anarquista (Reclus, 2002), de 1897. Mas sua geografia é essencialmente política, não de Estado, como magistralmente define Raffestin (1993), mas atenta à materialidade histórica das relações sociais, e ao mesmo tempo, é essencialmente engajada às questões de ordem ambiental, dimensionadas pelo debate das relações humanas com o meio geográfico. Uma geografia política libertária, contrária a tradicional geografia política e geopolítica autoritária, do Estado e do capital, a serviço do imperialismo moderno. Nos termos de Pierre George (1984), uma geopolítica das minorias.

O pensamento geográfico de Reclus, fundamentalmente, foi germinado na experiência espacial. Na medida em que o pesquisador foi interagindo com o objeto de estudo, ele foi formando sua compreensão do geográfico. Por sua vez, o geográfico não é suficientemente capturado somente pela experiência empírica; por isso, Élisée envolveu-se com as bases teóricas do mais importante centro acadêmico indicado para quem necessitasse estudar os fundamentos da geografia, na primeira metade do século XIX: a Universidade de Berlim, tendo Carl Ritter como principal professor.

A partir dessa perspectiva, a geografia para Reclus é compreendida por essas duas condições inseparáveis: a experiência empírica e a experiência teórica. Ele vai buscar viver, experimentar, ter contato, interagir para sentir, como também vai investigar, analisar e entender para compreender o geográfico, que não se restringe somente ao empírico e nem somente ao teórico. Quando um sobressai sobre o outro, o entendimento do que é geográfico fica comprometido como um todo. Por isso, o exercício teórico e prático será o tronco balizador da contribuição do pensamento reclusiano para a geografia.

A noção de experiência espacial não está relacionada somente à ambiência empírica do pesquisador com o objeto, mas ao significado de ele ser no mundo, de não se separar da realidade espacial que está imbuído, por ter sua existência intrinsecamente vinculada às condicionalidades e 
intencionalidades do meio que, por sua vez, preenche esse mesmo meio, produzindo condicionalidades e intencionalidades, e nesse processo contínuo, transforma seu eu e transforma sua condição de ser social pelas necessárias relações que o meio empreende, conforme abaixo demonstra Massey (2009, p. 26):

A imaginação do espaço como uma superfície sobre a qual nos localizamos, a transformação do espaço em tempo, a clara separação do lugar local em relação ao espaço externo são todos meios de controlar o desafio que a espacialidade, inerente ao mundo, apresenta. [...] No entanto, as constantes associações deixam efeitos residuais. Desenvolvemos meios de incorporar uma espacialidade à nossas maneiras de ser no mundo, aos modos de lidar com o desafio que a enorme realidade do espaço projeta. Produzidos por e envolvidos em práticas, das negociações cotidianas às estratégias globais, esses engajamentos implícitos de espaço retroalimentam e sustentam entendimentos mais amplos do mundo.

A experiência espacial é também uma condição de práxis, em virtude de que todo indivíduo ao se reconhecer enquanto parte integrante do meio, ao identificar sua condição intrínseca de intencionalidade, compreende que viver é essencialmente criar e transformar, e através da capacidade, advinda do conhecimento científico legado pela geografia, da cognoscibilidade do mundo e de seus fenômenos dinâmicos, do trabalho humano como eterno transformador do espaço, projeta-se sobre o mundo pelo signo da polis, pela condição de agente transformador. Então, o indivíduo recebe os estímulos do mundo ao vivenciá-lo, para nele se reconhecer, e estimula, por sua vez, o mundo que vivencia para mudá-lo.

Através de sua experiência espacial, Reclus projeta sua obra, que funciona como teoria dessa prática espacial, narrativas do mundo que almeja a reconciliação do ser humano com ele mesmo e com a terra, nos trilhos do humanismo fraternalista universal. A experiência espacial em Reclus é empírica, é teórica e é também política, por isso ela é também dimensão do social. Consequentemente, o espaço reclusiano é intrinsecamente social.

Souza (2000, p. 114) diz que "sob um ângulo mais abrangente, o espaço social pode ser visto como fruto das relações sociais, incluindo-se aí, além da transformação material pelo processo de trabalho, a territorialização através de projeções de poder e a atribuição de significados culturais.” A experiência espacial que Reclus projeta em sua obra, por ser 
oriunda de suas experiências existenciais, está dotada do significado social e das suas múltiplas atribuições.

Soja (1993, p. 100) tenciona sua discussão para a importância da "distinção entre o espaço per se, o espaço como um dado contextual, e a especialidade de base social, o espaço criado da organização e da produção sociais.” Neste sentido, a experiência espacial de Reclus está imbuída da compreensão de espaço enquanto dado contextual, mas que se projeta através de sua obra e das lutas sociais que ele envolveu pela espacialidade de base social, pois

o espaço socialmente produzido é uma estrutura criada, comparável a outras construções sociais resultantes da transformação de determinadas condições inerentes ao estar vivo, exatamente da mesma maneira que a história humana representa uma transformação social do tempo (Soja, 1993, p. 102).

Para entender a forma como o pensamento geográfico de Reclus foi gestado na experiência espacial, é importante destacar que ele foi fecundado da sua experiência com a natureza e com as lutas de classe, fundamentando sua geograficidade socioambiental libertária, que é a expressão do saber enquanto prática social, e enquanto movimento de autonomia do indivíduo, integrando, e não separando mais, as relações entre o sujeito e o objeto, pelo viés da intencionalidade do meio.

Santos (2004) destaca a importância do papel da intencionalidade como revisora da forma de produção do conhecimento, na qual "essa noção é igualmente eficaz na contemplação do processo de produção e de reprodução das coisas, considerados como um resultado da relação entre homem e o mundo, entre o homem e seu entorno" (Santos, 2004, p. 90), e em decorrência disso, "a intencionalidade seria uma espécie de corredor entre sujeito e o objeto" (Santos, 2004, p. 91). Nesse lugar reside o sentido de não separar a vida da obra de Reclus, observando a forma como ele reagiu e atuou enquanto promotor de intencionalidades na construção de uma geografia que é essencialmente vida, teoria e prática.

\section{Uma geografia libertária antes da hora?}

A formação do pensamento de Élisée Reclus ocorreu até os últimos dias de sua vida, não sendo interrompido nem mesmo diante dos sinais 
de esgotamento de suas forças vitais, sendo composto por diversificadas abordagens, conceitos e métodos de investigação e de explicação do caráter geográfico das ações humanas sobre a Terra.

Com a morte desse excêntrico personagem da geografia e do anarquismo, abriu-se uma enorme lacuna no que tange à continuidade dos trabalhos que ele incansavelmente vinha desenvolvendo ao longo dos anos, em meio à prisão, exílios e ativismo revolucionário, e por outro lado, à profunda dedicação ao trabalho científico, envolvendo-se com os periódicos especializados em geografia da época, bem como com as publicações mais engajadas do anarquismo, além de ter conquistado respeito de diversas sociedades de geografia distribuídas pela Europa e de ter construído um círculo de geógrafos anarquistas (Ferretti; Pelletier, 2013) que levaram pesquisas a diversos confins através de cursos e palestras; fizeram também pesquisas geográficas nos mais longínquos rincões da Terra, mantendo relações com pesquisadores de diversos lugares (Alavoine-Muller, 2003).

Todo esse trabalho foi bruscamente silenciado e sua última grande obra não obteve qualquer recepção pelo mundo científico e acadêmico. A principal hipótese se sustenta no forte teor libertário explícito neste texto, além de L'Homme et la Terre ter também causado intensa aproximação da geografia com a sociologia e a história, por estar marcada pela análise histórico-geográfica da ação do homem/mulher sobre a Terra, e por sua vez elevar a categoria espaço-temporal como a chave metodológica para a compreensão da relação entre sociedade e natureza.

É importante destacar que L'Homme et la Terre fechou a trajetória intelectual de Reclus, sendo publicada postumamente por seu sobrinho, Paul Reclus, a partir de 1905, fortalecendo assim as bases do discurso heterodoxo no interior da disciplina geografia, do final século XIX até a primeira metade do século XX, discurso esse também difundido por Piotr Kropotkin, Charles Perron, Léon Metchnikoff e Patrick Geddes.

Contrariando a historiografia tradicional, esses ativistas libertários introduziram, ainda no século XIX, o debate anarquista no interior dos estudos geográficos. Para a ortodoxia acadêmica, a geografia libertária apareceu antes da hora. Até a historiografia marxista, já no final do século XX, reconheceu somente parcialmente o legado da herança ácrata no pensamento geográfico. Herança essa que aflora dos subterrâneos na geografia mais atual. 
O posicionamento geográfico libertário é demarcado por duas abordagens principais: "um interesse sem apriorismo para as diferentes formações sociais, e um estudo das condições de uma relação harmoniosa dessas populações em sua relação recíproca com seu meio ecológico" (Creagh, 2011b, p. 28). Caracterizados por essas direções, Reclus, Kropotkin e Metchnikoff constituíram uma herança, embora não evidente para as academias dominantes, mas explicitamente viva nas lutas e nas práticas espaciais, que ressoou fecundamente sobre a tradição heterodoxa do pensamento urbano. "Podemos retraçar uma rede que vai de Patrick Geddes aos americanos Lewis Mumford, Paul Goodman, Ebenezer Howard, o inventor da cidade-jardim, e Jane Jacobs, ou, ainda hoje, James C. Scott, da Universidade de Yale” (Creagh, 2011b, p. 29).

Por outro lado, fora do campo dos estudos urbanos, a influência do pensamento geográfico libertário clássico ressoou significativamente a outros dois movimentos: a Internacional Situacionista, introduzido por Guy Debord; e o movimento da ecologia social libertária, sustentado em Gary Snyder, entre outros.

Paradoxalmente, o pensamento de Reclus, tanto no âmbito da geografia quanto no da anarquia, recebeu reconhecimento do contexto intelectual e de luta social que estava envolvido, mas este reconhecimento consequentemente foi fugaz, caindo em profundo esquecimento. $\mathrm{O}$ maior impacto da negligência se deu em sua obra mais paradigmática, seu tratado de geografia social, L'homme et la terre, que abriu possibilidades para novos direcionamentos da geografia, lançando-a no caminho de uma ciência engajada pela práxis espacial e pela transformação da sociedade desigual.

Reclus projetou uma geografia que nasceu da perspectiva ambiental, não naturalista e nem limitadamente física, como o fez Peschel, mas socioambiental, ligada à consciência do equilíbrio entre a ação humana e o meio, a exemplo da obra La Terre. Depois, em Nouvelle Géographie Universelle, incorporou a noção política no discurso espacial, mas, diferentemente da tradicional geografia política do Estado, vinculada ao imperialismo e ao colonialismo, anunciou caminhos para o federalismo libertário, a luta de classe em prol da liberdade autonomista dos grupos sociais subalternizados. Nessa mesma obra está contida a defesa do internacionalismo e do fraternalismo universal, confrontando os sentimentos nacionalistas e as guerras por território, escolhendo valorizar 
as identidades regionais, mas também, a diluição das fronteiras, a integração sociocultural e a implantação de formas alternativas de relações econômico-financeiras pelo comunalismo, a autogestão, o cooperativismo, entre outros. Por fim, L’Homme et la Terre congregou todos esses acúmulos alternativos, ou melhor, heterodoxas conjecturas sobre o saber geográfico, inaugurando o paradigma social libertário na geografia, efetivando no seu campo de saber a análise espaço-temporal para entender os processos de transformação da Terra pelos humanos, como ela é convertida em espaço e como a disputa por espaço evidencia a necessidade de organização equitativa do mesmo pela sociedade, a caminho da autogestão.

Essa linha de reflexão sobre a organização do pensamento reclusiano assemelha-se ao modo com que Ronald Creagh (2011a, p. 4, tradução minha) delineia essa geografia anarquista.

Pois ele [Reclus] recusa as fronteiras e as nações, crê na unidade da humanidade, e prefere sentir a espessura das relações sociais e das interações humanas com a Terra em vez de reduzir a vida ao esqueleto de mapas abstratos e de quadros estatísticos. A geografia reclusiana não terá de forma alguma o objetivo de fornecer mapas aos Estados maiores para suas guerras futuras, nem de proliferar o fanatismo patriótico. ${ }^{5}$

Esse itinerário constitutivo do pensamento geográfico de Reclus, que somente concluiu-se com sua morte, deu precedentes para a inauguração do que hoje se busca definir como geografia libertária, ou geografia das liberdades, que faz parte do grande conjunto de geografias dissidentes ou marginais. ${ }^{6}$

Toda a obra de Reclus constitui, pois, uma grande narrativa explicativa do mundo e de sua história, dividida em narrativas de sequencias temporais diversas. O que não deixa de colocar certas questões sobre a função desse tipo de epopeia em nossas sociedades pós-modernas e, mais precisamente, no seio dos movimentos contestatórios em geral e do anarquismo em particular. [...]

É sobre um duplo percurso que se lança a aventura intelectual de Reclus: o anarquismo e a geografia. No primeiro, ele contribui para a gênese do movimento conferindo à anarquia um conteúdo positivo, o anarquismo coletivista, fundado no apoio mútuo. Na segunda, [...] estamos diante de uma relação dialética entre quatro elementos: o espaço, o tempo, a sociedade, o indivíduo (Creagh, 2011b, p. 14). 
A heterodoxa geografia de Reclus é o exemplo prático do saber que se constrói em toda uma vida, que é tributária de suas vivências espaciais, germinada no solo fértil da academia alemã da primeira metade do século XIX, gestada no berço fecundo e enigmático da natureza pelas experiências existenciais oriundas das andanças e pousos. Por sua vez, a geografia reclusiana foi, desde o seu primeiro dia até o último, o subterfúgio para que se almejasse a luta de classe, a transformação da sociedade e a organização equitativa do espaço. Por isso, além de ter sido gestada na academia e germinada na natureza, ela foi educada nos movimentos sociais, na luta pela liberdade.

Não é uma geografia que, em certo momento da vida, com os acúmulos de experiência e após as condecorações que lhe colocou em posição confortável, simplesmente tornou-se acabada, monológica e monolítica, complacente ao discurso científico uniformizador. Ao contrário, é uma geografia pluridiscursiva, multifacetada e atenta aos movimentos complexos da sociedade e do espaço, por isso, profundamente se expressa como uma voz que incomoda, perturbando os silêncios determinados pela tradição acadêmica, que cala os desejos de gritos insubmissos.

Diante do contexto intelectual em que Reclus apresentou sua geografia, ela esteve equalizada aos temas e aos parâmetros de pesquisa da época. De certa forma, ele seguiu esse caminho trilhado pela academia dominante, contribuindo enormemente com as Sociedades de Geografia, trabalhando na mesma sintonia, se posicionando diante dos desafios de pesquisa, por isso fez também geografia ao modelo ortodoxo. Claro que o reconhecimento com as medalhas de ouro só vieram bem tarde, em virtude de erroneamente estarem acreditando na domesticação do espírito livre e insurgente do geógrafo anarquista.

Em meio ao contexto ortodoxo em que Reclus parcialmente figurou, ele deu enorme contribuição ao saber geográfico, sendo um dos principais responsáveis por garantir a continuidade e o desenvolvimento das pesquisas, avançando o saber da geografia enquanto ciência, após o desaparecimento de Ritter e Humboldt, fazendo essa conexão, conforme destaca Tatham (1959), dos clássicos fundadores aos inovadores estudos de Ratzel e La Blache (Robic, 2009).

Mesmo sendo personagem fundamental dentro deste delicado momento de defasagem dos estudos em que a geografia passou, 
transportando grande parte da carga dessa tradição até o novo ciclo de renovação localizado logo à sua frente, Reclus não foi reconhecido como agente desse trabalho de passagem, de transposição dos desertos do saber geográfico. Tanto Hettner como Ratzel e La Blache, desconsideraram a geografia reclusiana, porém, se apoiaram em diversos conceitos e linhas de reflexão por ela aberta (Lacoste, 1988), mas flagrantemente lançaram o nome de Reclus no esquecimento, por sua geografia ser profundamente incompatível à orientação político-ideológica que a academia estabelecia como aceitável. Seus novos representantes, detentores do direito de inventário do fluxo historiográfico, confortavelmente sentados em suas cátedras da seletividade intelectual, tinham que zelar para que não ocorresse a penetração de impurezas no árduo trabalho de filtragem e decantação da institucionalização e da cientificização do saber geográfico.

Essas grandes geografias, que se posicionavam como a eleita, responsável por trilharem os novos caminhos da geografia, estando à frente, dirigindo os melhores percursos a se tomar, tinha como principal missão ou destino manifesto, saber da melhor forma de incluir, descartar, colocar no trilho ou desviar essas pequenas geografias que representassem incongruência ao modelo intelectual ortodoxo.

Mas a geografia de Reclus estava equalizada às grandes geografias, sempre esteve conectada ao que se melhor buscava fazer desse campo do saber, contribuindo com o projeto de consolidação e de status científicoacadêmico. Ideologicamente, a geografia libertária reclusiana intuía curtocircuito (tomando a expressão de Kuhn, 1971) ao paradigma ideológico dominante da geografia. Este, mesmo defendendo que não possuía nenhuma adesão política, paradigma situado na segunda metade do século XIX e início do século XX, era adepto de correntes de pensamento vinculadas à perspectiva liberal, tendo geógrafos que defendiam o evolucionismo darwinista, outros, o neokantismo, como também havia aqueles que se alinhavam ao regionalismo e ao nacionalismo. Todos estavam cientes da importância da presença do Estado e do capital como motores indutores dos interesses da produção do saber geográfico. O ponto de conflito entre a geografia de Reclus e de seus contemporâneos se dava, justamente, no que concerne ao seu caráter ideológico: eticamente era uma geografia das liberdades, sustentada na corrente teórica do anarquismo.

Élisée fez uma geografia conectada ao movimento de produção do conhecimento de sua época, totalmente coerente aos desafios e 
necessidades de pesquisa, mas consequentemente, por ser uma geografia engajada ao anarquismo, pois todas as geografias estão engajadas direta ou indiretamente a algum interesse, foi desconectada do contexto acadêmico-científico.

A historiografia dominante defende que, em virtude de seu profundo engajamento, atitude inaceitável para a época, esta geografia não foi essencialmente científica, por isso não mereceu ter ganhado devida atenção, pois tinha como objetivo pôr fim às liberdades e não à pura e neutra produção do conhecimento.

Outras historiografias mais recentes apontam que esta geografia libertária, forjada por Reclus e demais estudiosos deste círculo anarquista comunista, apareceu antes da hora, portando discurso muito heterodoxo para a época. Esse tipo de compreensão constrói profundos equívocos no estudo e ensino de história da geografia, pois tenta impor que em cada período devem-se aparecer determinadas doutrinas, e em cada época cabe determinado uso metodológico. Nunca um saber surge fora de sua época, são as condições de definição e de classificação pela historiografia da ciência que o evidencia, descarta, ou mesmo o faz, na medida em que os interesses da época querem melhor recepcioná-lo, dando a forma que a época melhor quer vislumbrá-lo, forma essa que não cause escatologias.

É mais do que necessário e coerente uma geografia libertária em pleno século XIX, pois nesse efervescente século, o liberalismo com seus imperialismos e industrialismo causaram graves acúmulos de pobreza, promoveram sangrentos conflitos e conquistas territoriais, redefinindo fronteiras, forjando e apagando outras, consumindo vidas, recursos, força de trabalho e liberdades, para nutrir os agentes de poder do capital e do Estado imperial sobre os ombros dos trabalhadores.

Nessa mesma época surgiram diversos socialismos, as admiráveis teorias científicas de Marx, tão res-significadas até hoje, os diversos anarquismos, tão suprimidos, formas de culturalismo e também os extremados niilismos. As questões do território, da região, dos lugares, das identidades, da exploração da mulher e do homem e da ação predatória destes sobre a natureza, estavam consideravelmente evidentes para que a geografia ficasse omissa, calada e neutra quanto às mazelas que eram jogadas nos rostos destes especialistas do espaço geográfico. Se por sua vez fizeram geografias que justificassem essas ingerências do capital e do Estado, não era estranho que também fizessem geografias que contestassem o poder em prol da liberdade a qualquer custo. 
A geografia libertária de Reclus não apareceu antes da hora e sim na hora certa, visto que tinha campo fecundo para surgir e se desenvolver, e fez isso com a materialização de larga produção escrita, com ampla atuação profissional, pois foram onze anos intensos de aula e de pesquisa (Giblin, 1986).

Por ter sido uma geografia vivencial diluída na luta revolucionária, seu pouco reconhecimento e má leitura que a trouxe até os dias de hoje, pela via dos manuais de história da geografia e a defasada capacidade explicativa contida no ensino dessa abordagem, nauseada pela atmosfera da historiografia dominante, induz a pensar que o campo do saber geográfico, como um todo, perdeu muito com essas falhas historiográficas do passado.

\section{Conclusão}

A reflexão acerca da presença de Reclus na história do pensamento geográfico e o horizonte epistemológico do anarquismo que o mesmo difundiu nos meandros do pensar espacial, levam a destacar que seu pensamento foi gestado através da experiência espacial, marcada pelo confronto entre o entendimento da natureza e os embates das lutas de classe, formando sua geograficidade da dissidência, que buscou veicular o discurso das liberdades, da organização do espaço, do equilíbrio e da autogestão do território à práxis espacial engajada.

O elemento definidor da origem desse pensamento insubmisso é o milieu e toda uma vida de experiências, investigações e busca de desvendamentos, desmistificação e explicações; por outro lado, cabe à luta de classe, engajada e revolucionária, fonte de contestação ao poder e à opressão, tendo nas liberdades a referência fundadora de um pensamento rebelde. Esses dois elementos se juntam para formar a síntese do pensamento geográfico socioambiental e libertário de Reclus, que pode ser compreendido, de uma forma geral, como a geograficidade libertária.

\section{Notas}

1 Este trabalho é fragmento da tese de doutorado intitulada Geograficidade libertária em Élisée Reclus: contribuição heterodoxa à história da geografia, orientada pelo professor Dr. Eliseu Savério Sposito, na Faculdade de Ciências e Tecnologia - UNESP, Presidente Prudente - SP. 
2 A expressão foi retirada do prefácio de L'homme et la terre, em que Reclus (1905, p. I-II) diz: "Apparus comme un point dans I'infini de l'espace, ne connaissant rien de nos origines ni de nos destinées, [...], nous aurions mauvaise grâce à formuler des règles d'évolution à inconnu, à battre le brouillard, dans l'espérance de lui donner une forme précise et définitive."

Tradução minha: "Surgidos como um ponto no infinito do espaço, sem nada conhecer de nossas origens nem de nossos destinos, [...], estaríamos impossibilitados a formular regras de evolução ao desconhecido, a superar a névoa, na esperança de dar-lhe uma forma precisa e definitiva."

3 Para um entendimento detalhado da vida e da obra de Reclus, vinculado às suas experiências geográficas e históricas, ver Nettlau (1928), Sarrazin (1985) e Giblin (1986).

4 "Plus tard, beaucoup plus tard, chacun se découvre nômade ou sédentaire, amaterus de flux, de transports, de déplacements, ou passionné de statisme, d'immobilisme et de racines".

5 “Car il [Reclus] refuse les frontières et les nations, il croit à l'unité de l'humanité, et il préfère faire sentir l'épaisseur des relations sociales et des rapports humains avec la Terre plutôt que de réduire la vie au squelette de cartes abstraites et de tableaux statistiques. La géographie reclusienne n'aura pas pour but de fournir des cartes d'étatmajor pour les guerres futures, ni d'inculquer le patriotisme."

6 A geografia libertária, segundo Creagh (2011b, p. 25), "situa-se na grande tradição da dissidência, aquela que questiona os poderes, ou, para ser mais preciso, as diversas formas de dominação e exploração." Ainda segundo o geógrafo anarquista estadunidense, "Tal geografia também é uma arma contra as ideologias imperialistas", e Reclus foi o principal expoente dessa forma heterodoxa de fazer geografia, reluzindo subterraneamente suas ideias sobre diversas possibilidades radicais de pensar a dimensão geográfica, no que hoje as geógrafas Blunt e Wills (2000) denominam de geografias dissidentes.

\section{Referências}

ALAVOINE-MULLER, S. Un globe terrestre pour l'Exposition Universelle de 1900. L’utopie géographique d’Élisée Reclus. L’Espace Géographique. Berlin, v. 32, n. 2, 2003, p. 156-170.

ALAVOINE-MULLER, S. Élisée Reclus ou la géographie pour tous. In: BORD, J.P. et. al. (Ed.). Élisée Reclus - Paul Vidal de la Blache. Le géographe, la citéet le monde hier et aujourd'hui (autour de 1905). Paris: L'Harmattan, 2009. p. 213-225.

BLUNT, A.; WILLS, J. Dissident Geographies: an introduction to radical ideas and practices. Edimburgo: Person Education Limited, 2000.

BOINO, P. Plaidoyer pour une géographie reclusienne. Réfractions, Recherches et expressions anarchistes, n. 4, Espaces d'anarchies - Automne, 1999, p. 1-9.

BOINO, P. O pensamento geográfico de Élisée Reclus. In: RECLUS, E. Da ação humana na geografia física. Geografia comparada no espaço e no tempo. São Paulo: Imaginário. Expressão e Arte, 2010. p. 9-39. 
CREAGH, R. Élisée Reclus et les États-Unis: Genèse d'une géographie. In: COLÓQUIO INTERNACIONAL: ÉLISÉE RECLUS E A GEOGRAFIA DO NOVO MUNDO, 2011, São Paulo. Anais... São Paulo: Laboratório de Geografia Política, Departamento de Geografia da Universidade de São Paulo, USP, 2011a.

CREAGH, R. O que é uma geografia das liberdades? In: CREAGH, R. et al. Élisée Reclus e a geografia das liberdades. São Paulo: Imaginário. Expressão e Arte, 2011b.

FERRETTI, F. Esclaves libérés et vols d'histoire: la géographie d'Élisée Reclus et l'Afrique subsaharienne. Élisée. Revista de Geografia da UEG, Goiânia, v. 1, n. 2, p. 1-24, jul./dez 2012.

FERRETTI, F., PELLETIER, P. "Indígenas do universo": espaço, dominação e práticas de libertação social na obra dos geógrafos anarquistas Elisée Reclus, Piotr Kropotkin e Léon Metchnikoff. Revista Território Autônomo, n. 2, p. 5-16, outono de 2013.

FOUCAULT, M. Arqueologia do saber. 8. ed. São Paulo: Forense Universitária, 2013.

GEORGE, P. Géopolitique des minorités. Paris: PUF, 1984.

GIBLIN, B. Élisée Reclus: géographie, anarchisme. Hérodote, Paris, n. 117, $2^{\circ}$ trimestre, Paris, p. 30-51, 1976.

GIBLIN, B. Introducción y selección de textos. In: RECLUS, E. El hombre y la tierra. México: Fondo de Cultura Económica, 1986.

KUHN, T. S. La estructura de las revoluciones científicas. México: Fondo de Cultura Económica, 1971.

LACOSTE, Y. A geografia, isso serve, em primeiro lugar, para fazer a guerra. Campinas: Papirus, 1988.

LACOSTE, Y. Élisée Reclus, une très large conception de la géographicité et une bienveillante géopolitique. Hérodote, Paris, n. 117, $2^{\circ}$ trimestre, p. 29-52, 2005.

MASSEY, D. Pelo espaço. Uma nova política da espacialidade. Rio de Janeiro: Bertrand Brasil, 2009.

MOSQUETE, T. V. Eliseo Reclus: compromiso social y libertad científica del siglo XIX para el siglo XXI. In: ARNAU, X. et. al. (Ed.). Ciència i Compromís Social. Élisée Reclus (1830 - 1905) i la Geografia de la Libertat. Barcelona: Publicaciones de la Residència D’Investigadors, 2007. p. 11-49.

NETTLAU, M. Eliseo Reclus (1830-1905): la vida de un sábio justo y rebelde. Barcelona: Biblioteca de la Revista Blanca, 1928.

ONFRAY, M. A política do rebelde. Tratado de resistência e insubmissão. Rio de Janeiro: Rocco, 2001.

ONFRAY, M. Théorie du Voyage. Poétique de la géographie. Paris: Librairie Générale Française, 2007.

ONFRAY,M.Apotência de existir. Manifesto hedonista. São Paulo: Martins Fontes, 2010.PELLETIER, P. Élisée Reclus, théorie géographique etthéorie anarchiste. 
In: COLÓQUIO INTERNACIONAL: ÉLISÉE RECLUS E A GEOGRAFIA DO NOVO MUNDO, 2011, São Paulo. Anais... São Paulo: Laboratório de Geografia Política, Departamento de Geografia da Universidade de São Paulo, USP, 2011.

RAFFESTIN, C. Por uma geografia do poder. São Paulo: Ática, 1993.

RECLUS, É. L’hommeet la terre. 6 Tomes. Paris: Librairie Universelle, 1905.

RECLUS, É. Correspondance. Septembre 1889 - Juillet 1905. Tome 3. Paris: Alfred Costes, 1911.

RECLUS, É. A evolução, a revolução e o ideal anarquista. São Paulo: Imaginário, 2002.

ROBIC, M-C. De la relativité... Élisée Reclus, Paul Vidal de la Blache et l'espacetemps. In: BORD, J-P. et. al. (Ed.). Élisée Reclus - Paul Vidal de la Blache. Le géographe, la citéet le monde hier et aujourd'hui (autour de 1905). Paris: L’Harmattan, 2009.

ROQUES, G. Élisée Reclus geógrafo: uma herança ainda virtual. In: COÊLHO, P. A. (Org.). Élisée Reclus e a geografia das liberdades. São Paulo: Imaginário, 2011. p. 35-60.

SANGUIN, A-L. De Reclus à Vidal: la prise en compte du politique dans la pensée géographique française. In: BORD, J-P. et. al. (Ed.). Élisée Reclus - Paul Vidal de la Blache. Le géographe, la citéet le monde hier et aujourd'hui (autour de 1905). Paris: L'Harmattan, 2009. p. 283-289.

SANTOS, M. A natureza do espaço. Técnica e tempo, razão e emoção. 4. ed. São Paulo: EdUSP, 2004.

SARRAZIN, H. Élisée Reclus, ou, la passion du monde. Paris: La Découverte, 1985.

SOJA, E. W. Geografias pós-modernas: a reafirmação do espaço na teoria social crítica. Rio de Janeiro: Zahar, 1993.

SOUZA, M. L. de. O desafio metropolitano. Um estudo sobre a problemática sócio-espacial nas metrópoles brasileiras. Rio de Janeiro: Bertrand Brasil, 2000.

TATHAM, G. A geografia no século dezenove. Boletim Geográfico. Conselho Nacional de geografia. IBGE: Ano XVII, n. 150, p. 198 - 226, maio/junho de 1959.

José Vandério Cirqueira - Possui graduação em Geografia pela Universidade Estadual de Goiás, mestrado em Geografia pela Universidade Federal de Goiás e doutorado pela Universidade Estadual Paulista. Atualmente é professor do Instituto Federal de Goiás. 